\title{
Malignant transformation of ovarian dermoid: a rare case
}

\author{
Pesona Grace Lucksom*, Nikhil Sebastian, Dipika Pradhan, Rashmi Ritu
}

Department of Obstetrics and Gynecology, Sikkim Manipal Institute of Medical Sciences, $5^{\text {th }}$ Mile Tadong, East Sikkim - 737102, India

Received: 20 September 2013

Accepted: 5 October 2013

*Correspondence:

Dr. Pesona Grace Lucksom

E-mail: pesonadoc@gmail.com

(C) 2013 Lucksom PG et al. This is an open-access article distributed under the terms of the Creative Commons Attribution Non-Commercial License, which permits unrestricted non-commercial use, distribution, and reproduction in any medium, provided the original work is properly cited.

\begin{abstract}
Mature cystic teratoma also known as the dermoid cyst is the most common benign tumor of the ovary $(10-20 \%)$ in women of reproductive age. Malignant transformation in a dermoid is very rare $(<2 \%)$ with squamous cell carcinoma being the most common malignancy. A total of 36 ovarian cysts have been operated in our hospital from the year February 2007 to April 2012 of which about 90\% were dermoid but no case of ovarian dermoid turned malignant have been reported till date in our state, Sikkim, India. We report a rare case of dermoid cyst of ovary in a $47 \mathrm{yr}$ old woman which had malignant transformation. Surgeons should keep the chance of malignant transformation in mind when faced with a dermoid cyst especially in older patients or in larger than usual so that the best can be done for the patient regarding the staging of the disease and its further management.
\end{abstract}

Keywords: Cyst, Dermoid, Ovary, Transformation, Malignancy

\section{INTRODUCTION}

Mature cystic teratoma (MCT) commonly known as dermoid cyst is the most common benign tumor of the ovary accounting for $10-20 \%$ of all ovarian tumors in women of reproductive age. ${ }^{1}$ Approximately $90 \%$ are unilateral with a variable size of $5-10 \mathrm{~cm}$. MCT is composed of well-differentiated tissues derived from the three germ cell layers. Malignant transformation in a dermoid is very rare, about $1-2 \% .^{2}$ We report a rare case of dermoid cyst of ovary which had malignant transformation.

\section{CASE REPORT}

A 47 years women attended our OPD on $9^{\text {th }}$ April 2012 with an Ultrasonography report (done on $10^{\text {th }}$ October 2011) showing bulky uterus with a small anterior wall myoma and a right adnexal mass (Dermoid cyst?). She complained of menstrual irregularity, heaviness and dull pain over the lower abdomen for the past one year which had increased in intensity for about 15 days for which she wanted treatment. She had sinus bradycardia and was a chronic hypertensive on medication. Her abdominal examination revealed a palpable mass about 16 weeks on the right iliac fossa. On vaginal examination uterus was normal in size and separate from the mass but was pushed towards the left as the cystic mass occupied the right fornix. An ultrasound repeated on $10^{\text {th }}$ April 2012 to confirm the previous findings and also to know the size of the dermoid showed right sided ovarian dermoid about $14 \mathrm{~cm} \mathrm{X} 10.4 \mathrm{~cm}$ in size. Laparotomy was done on $11^{\text {th }}$ April 2012. On opening the abdomen there was no adhesion and no free peritoneal fluid. Uterus was normal in size and shape, left sided tube and ovary were normal, right sided ovary showed the presence of a large cystic mass about $14 \mathrm{~cm} \times 10 \mathrm{Cm}$. The cystic mass had regular and smooth surface with the capsule intact. There was a small firm mass $(4 \mathrm{~cm} \mathrm{X} 4 \mathrm{~cm})$ attached over the superior surface of the cyst. Patient wanted the uterus and the opposite ovary to be preserved if they were normal so according to patient's request and the cyst being dermoid (which is benign in almost all cases) with no features of malignancy at the time of laparotomy, uterus and the opposite ovary were left behind while right sided 
salpingo-oophorectomy was done. The specimen was cut in the operation theater which showed presence of sebaceous substance and hairs within the cyst. Cut specimen was sent for histopathological examination. Post operative period was uneventful and the patient was discharged on the $5^{\text {th }}$ post operative day. Histopathological report showed squamous cell carcinoma over the solid areas of the cyst wall. Impression was mature cystic teratoma with malignant transformation. Patient was then referred to an Oncology center for further management.

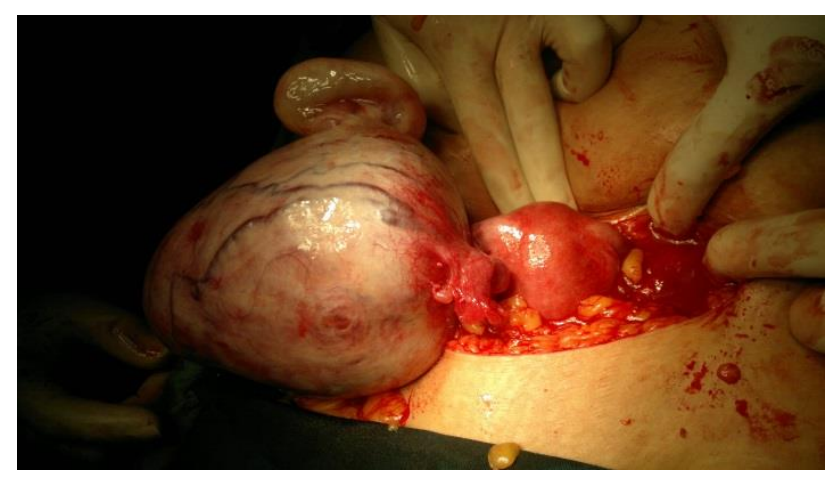

Figure 1: A large cystic mass.

\section{DISCUSSION}

Mature cystic teratoma are mostly benign so Squamous Cell CA arising from an MCT is a rare pathologic event $(<2 \%)$. It is difficult to diagnose malignancy in dermoid as there are no specific signs or symptoms related to malignancy arising in a dermoid. Even in this patient, other than the size of the tumour, there were no features suggesting malignancy. A total of 36 ovarian cysts have been operated in our hospital from the year February 2007 to April 2012 of which about 90\% were dermoid but no such case of ovarian dermoid turned malignant have been reported till date in our State, Sikkim, India. Risk factors for malignancy in a mature cystic teratoma have been found to include age over 45 years, tumor diameter greater than $10 \mathrm{~cm}$, and rapid growth. ${ }^{3}$ SCC arising in an MCT has been observed usually in relatively older patients particularly after menopause. Although MCT presents in a wide range of sizes, larger tumors correlate with an increased risk of malignant transformation. In our case, the tumor diameter was around $14 \times 10 \mathrm{~cm}$, which is larger than a typical benign cyst. A study by Kikkawa et al. ${ }^{4}$ showed that a tumor diameter of larger than $9.9 \mathrm{~cm}$ had $86 \%$ sensitivity for malignancy in their series. In general, it is recommended that a diameter equal or greater than $10 \mathrm{~cm}$ or an ovarian MCT demonstrating rapid growth should be suspected for malignancy. The prognosis for these tumors with features of metastasis has been often reported to be very poor with a five-year survival of only $15-30 \%$. $^{2}$ Better prognosis has however been reported when the malignant element is an SCC compared with adenocarcinoma or sarcoma. ${ }^{2}$ Also early detection and treatment of the SCC has better prognosis as reported in a case reports by $\mathrm{S}$. Tangjitgamol et al. ${ }^{5}$ In Peterson's study of 190 cases $^{6}$, metastases were noted in $64 \%$ of the patients and large intestine (23\%) was most frequently involved. In a recently published case series of 11 cases, metastasis was noted in only $18 \%$ of the patients ( 2 cases), and the sites were rectum and urinary bladder. ${ }^{7}$ Surgery has been opted as the main therapeutic approach to an ovarian MCT with malignant transformation. ${ }^{6}$ For early stage IA disease especially for nulliparous and young patients who desire future fertility, conservative unilateral oophorectomy without further postoperative treatment may be justified, while in postmenopausal women, total removal of the reproductive organs would seem to be the procedure of choice. ${ }^{8}$ The adjuvant therapy for SCC arising from an MCT has not been yet established. ${ }^{6}$

In conclusion, surgeons should keep the chance of malignant transformation in mind when faced with dermoid cyst which may appear benign during laparotomy especially in older patients or in larger than usual so that the best can be done for the patient regarding the staging of the disease and its further management.

\section{ACKNOWLEDGEMENTS}

We acknowledge the Department of Pathology of SMIMS for providing us with all necessary help regarding the histopathological report and also the OBG staff for their support.

\section{REFRENCES}

1. Scully RE. Dermoid cysts. In: Tumours of the ovary and maldeveloped gonads. Atlas of tumour pathology. Second series, Fascile 16. Washington, DC: armed Forces Institue of Pathology 1979:255-68.

2. Kurman R J. Blaustein's Pathology of the Female Genital Tract. 5th ed. New York: Springer Verlag; 2002.

3. Al-Rayyan ES, Duqoum W, Sawalha MS, Nascimento MC, Pather S, Dalrymple CJ, Carter JR. Secondary malignancies in ovarian dermoid. cyst Saudi Med J. 2009;30(4):524-528.

4. Kikkawa F, Nawa A, Tamakoshi K, Ishikawa H, Kuzuya K, Suganuma N, et al. Diagnosis of squamous cell carcinoma arising from mature cystic teratoma of the ovary. Cancer. 1998; 82: 2249 2255

5. Tangjitgamol S, Manusirivithaya S, Sheanakul C, Leelahakorn S, Thawaramara T,. Jesadapatarakul S. Squamous cell carcinoma arising from dermoid cyst: Case reports and review of literature: International Journal of Gynecological Cancer 2003;13:558-563.

6. Peterson WF. Malignant degradation of benign cystic teratomas of the ovary: a collective review of the literature. Obstet Gynecol Surv. 1957;12:793-820. 
7. Rim SY, Kim SM, Choi HS. Malignant transformation of ovarian mature cystic teratoma. Int J Gynecol Cancer. 2006; 16: 140 - 144.

8. Tseng CJ, Chou HH, Huang KG, Chang TC, Liang $\mathrm{CC}$, Lai $\mathrm{CH}$, et al. Squamous cell carcinoma arising in mature cystic teratoma of the ovary. Gynecol Oncol. 1996; 63: $364-370$.
DOI: $10.5455 / 2320-1770 . i j r \operatorname{cog} 20131244$

Cite this article as: Lucksom PG, Sebastian N, Pradhan D, Ritu R. Malignant transformation of ovarian dermoid: a rare case. Int J Reprod Contracept Obstet Gynecol 2013;2:698-700. 